\title{
BMJ Open Impact of the herpes zoster vaccination programme on hospitalised and general practice consulted herpes zoster in the 5 years after its introduction in England: a population-based study
}

\author{
Nick Andrews (10 , , Julia Stowe, ${ }^{2}$ Galena Kuyumdzhieva, ${ }^{2}$ Bersabeh Sile, ${ }^{2}$ \\ Ivelina Yonova, ${ }^{3,4}$ Simon de Lusignan (1) ,3,4 Mary Ramsay, ${ }^{2}$ Gayatri Amirthalingam ${ }^{2}$
}

To cite: Andrews N, Stowe J, Kuyumdzhieva G, et al. Impact of the herpes zoster vaccination programme on hospitalised and general practice consulted herpes zoster in the 5 years after its introduction in England: a populationbased study. BMJ Open 2020;10:e037458. doi:10.1136/ bmjopen-2020-037458

- Prepublication history and additional material for this paper are available online. To view these files, please visit the journal online (http://dx.doi. org/10.1136/bmjopen-2020037458).

Received 06 February 2020 Revised 16 April 2020 Accepted 28 May 2020

Check for updates

(C) Author(s) (or their employer(s)) 2020. Re-use permitted under CC BY-NC. No commercial re-use. See rights and permissions. Published by BMJ.

${ }^{1}$ Statistics Modelling and Economics Department, Public Health England, London, UK ${ }^{2}$ Immunisation, Hepatitis and Blood Safety Department, Public Health England, London, UK ${ }^{3}$ Royal College of General Practitioners Research and Surveillance Centre, London, UK ${ }^{4}$ Nuffield Department of Primary Care Health Sciences, University of Oxford, Oxford, UK

Correspondence to

Prof Nick Andrews;

nick.andrews@phe.gov.uk

\section{ABSTRACT}

Objectives To assess the impact of herpes zoster vaccination in the 5 years after introduction for 70 - to 79-year-olds in England in September 2013.

Design Population based ecological impact assessment. Setting Hospitals covering the whole English population for the period 2008 to 2018 and 293 general practices (GP) for the period 2005 to 2018, in England.

Participants Over the period the population contributed 117.5 million person-years for hospitalisation events and 6.96 million person-years for GP events in individuals aged 60 to 89.

Interventions Live attenuated herpes zoster vaccination (Zostavax), first used on $1^{\text {st }}$ September 2013, in 70- and 79-year-olds with continued use in new 70 year-olds and with a staged catch-up of those aged 71 to 78 years in 2013.

Outcome measures Herpes zoster and postherpetic neuralgia (PHN) consultation and hospitalisation rates in age-cohorts according to vaccine eligibility. Incidence rate ratios in age-cohorts eligible for vaccination compared with those non-eligible were calculated by Poisson regression. This was used to estimate prevented cases and, along with vaccine coverage, to estimate vaccine effectiveness.

Results Large and prolonged reductions in herpes zoster and PHN consultations and hospitalisations were observed in the 5 years post-implementation. For example, in 79 year-olds first eligible in 2013, the incidence rate ratio for consultations 5 years later was $0.65(95 \% \mathrm{Cl}$ : 0.52 to 0.81 ). Over the whole period an estimated 40 500 fewer zoster consultations and 1840 fewer zoster hospitalisations occurred because of the vaccination programme. These reductions were consistent with effectiveness in the routine cohorts (vaccinated aged 70) of between $37 \%$ (for hospitalised zoster) and $75 \%$ (for PHN consultations) and, in catch up cohorts (vaccinated aged 78 to 79 ) of between $49 \%$ (for hospitalised PHN) and $66 \%$ (for PHN consultations).

Conclusion Given the clear and sustained impact of herpes zoster vaccination over the 5-year period since introduction, optimising vaccination coverage is important to attain maximum benefit.
Strengths and limitations of this study

- Use of a large general practice cohort and national hospital episode data has allowed precise estimation of the impact of the herpes zoster vaccination programme.

- Five years of follow-up post vaccine implementation has allowed detailed assessment of the duration of protection against herpes zoster and postherpetic neuralgia.

- The staged introduction of the vaccine with catch-up in different cohorts over time has allowed a robust analysis of impact accounting for time trends and age effects.

- As an impact study it was only possible to indirectly assess vaccine effectiveness using impact estimates and coverage data.

- Assessing duration of protection was approximate because up to $10 \%$ of individuals were vaccinated after the first year they were targeted.

\section{INTRODUCTION}

The herpes zoster (shingles) vaccine Zostavax (Zoster Vaccine Live; Merck \& Co, Kenilworth, New Jersey, USA) was introduced in the UK on $1^{\text {st }}$ September 2013 following the recommendation for its use in immunocompetent 70 - to 79-year-olds by the UK's Joint Committee on Vaccination and Immunisation (JCVI). ${ }^{12}$ The aim of the programme is to boost individuals' pre-existing immunity to varicella zoster virus (VZV) and prevent herpes zoster which is caused by reactivation of latent VZV. Herpes zoster is typically characterised by a unilateral dermatomal vesicular rash which can lead to complications including postherpetic neuralgia $(\mathrm{PHN})$ in which pain persists for more than 3 months after rash onset, especially in immunocompromised individuals and older adults. ${ }^{3}$ Zostavax is a live attenuated 
Table 1 Eligibility for shingles vaccination in England

Age on 1

Sept 2013 First became

Birth cohort (years) eligible

\begin{tabular}{lll}
\hline Routine cohorts & & \\
2 Sept $1942-1$ Sept 1943 & 70 & $2013-14$ \\
2 Sept $1943-1$ Sept 1944 & 69 & $2014-15$ \\
2 Sept $1944-1$ Sept 1945 & 68 & $2015-16$ \\
2 Sept $1945-1$ Sept 1946 & 67 & $2016-17$ \\
2 Sept $1946-1$ Sept 1947 & 66 & $2017-18$ \\
2 Sept $1947-1$ Sept 1948 & 65 & $2017-18$ (when \\
& & turning 70)
\end{tabular}

Catch-up cohorts

\begin{tabular}{lll}
\hline Sept $1933-1$ Sept 1934 & 79 & $2013-14$ \\
\hline 2 Sept $1934-1$ Sept 1936 & 77 to 78 & $2014-15$ \\
\hline 2 Sept $1936-1$ Sept 1937 & 76 & $2015-16$ \\
\hline Sept $1937-1$ Sept 1938 & 75 & $2016-17$ \\
2 Sept $1938-1$ Sept 193974 & $2017-18$ \\
2 Sept $1939-1$ Sept 1940 & 73 & $\begin{array}{l}2017-18 \text { (when } \\
\text { turning } 78)\end{array}$
\end{tabular}

Individuals remain eligible until their $80^{\text {th }}$ birthday.

herpes zoster vaccine containing the same Oka VZV strain as the childhood varicella vaccine (Varivax) but at a higher dose. Single dose efficacy from clinical trials of $38 \%$ against shingles and $67 \%$ against $\mathrm{PHN}$ over a 3 -year follow-up has been demonstrated in adults $\geq 70$ years of age with more recent evidence indicating efficacy maintained at about $30 \%$ for herpes zoster and PHN up to 8 years after vaccination. ${ }^{45}$ The choice of target age group was based on a cost-effectiveness analysis which incorporated the age-specific incidence of herpes zoster and PHN, ${ }^{6}$ the decline in vaccine efficacy with age and the estimated duration of vaccine-induced protection. ${ }^{1}$

In the first year of the programme (2013 to 2014), a single dose of vaccine was offered to adults aged 70 (routine cohort) and 79 years (catch up) on $1^{\text {st }}$ September 2013. In the following 4 years further routine and catch-up cohorts were offered the vaccine as outlined in table 1 , with the most recent cohorts offered the vaccine as they turned 70 or 78 years of age rather than by age at September 1 of the year.

Evaluation of the vaccine programme 3 years following its introduction demonstrated a clear impact in these target ages on general practice (GP) consultations for herpes zoster and PHN with herpes zoster incidence reducing from about nine to six per 1000 person-years. ${ }^{7}$ In addition, vaccine effectiveness in the 3-year period has been demonstrated as $64 \%$ (95\% CI: $60 \%$ to $68 \%)$ against GP consultations for herpes zoster and 81\% (95\% CI: $61 \%$ to $91 \%$ ) for PHN. ${ }^{8}$ In this paper, we extend the previous 3-year evaluation to a 5-year period post introduction, which allows a fuller assessment of waning. We also assess impact on hospitalisations for herpes zoster and PHN allowing a more complete evaluation of the reduction in disease burden.

\section{METHODS}

\section{Data sources}

General practice data on consultations and vaccine uptake

The Royal College of General Practitioners (RCGP) Research and Surveillance Centre (RSC) is a sentinel primary care network representing over $1 \%$ of the English population that is geographically representative of the general population. ${ }^{9}$ In March 2019 we obtained data on herpes zoster, PHN and herpes zoster vaccinations for the period from $1^{\text {st }}$ October 2005 to $30^{\text {th }}$ September 2018 for patients aged 60 to 89 years from all 293 practices in the network. We also obtained denominator data for patients registered each month, stratified by age at $1^{\text {st }}$ September 2013, year/month, gender and GP practice. Events were identified using Read codes (coded thesaurus of clinical terms used for recording patient findings and procedures-see online supplementary file 1$).{ }^{10}$ For analysis we aggregated these data using the same strata as for the denominator data. Herpes zoster consultations and PHN consultations were dropped if they occur within 12 months of a previous consultation.

\section{Hospital admissions data}

For hospital admissions we used Hospital Episode Statistics (HES) Admitted Patient Care, which contains individual level hospital admissions for all at National Health Service hospitals in England. ${ }^{11}$ In August 2019, we obtained all Finished Consultant Episodes for the period from $1^{\text {st }}$ October 2008 to $30^{\text {th }}$ September 2018 , for patients aged 60 to 89 years with an International Classification of Diseases (ICD) code B022 herpes zoster or with ICD code G530 PHN in any of the patients 20 diagnosis fields on discharge. We required a minimum gap of 12 months between episodes. We calculated age in September before the year they became ill and aggregated data by age and month/year of admission. To obtain denominators we obtained England Office for National Statistics population statistics by year of age for the period 2008 to 2017 and matched these to the appropriate numerator. ${ }^{12}$ We then generated the age on $1^{\text {st }}$ September 2013 so that the vaccine eligible cohorts could be allocated.

\section{Statistical analysis}

We defined age cohorts according to participants age on $1^{\text {st }}$ September 2013, which allowed us to identify those targeted in each year of the programme as given in table 1. Those becoming eligible by turning 70 or 78 in 2017 had low uptake in 2017 to 2018 and we therefore excluded these cohorts from the impact analysis from $1^{\text {st }}$ October 2017 by treating them as a separate group for this period. We calculated cumulative vaccine uptake from the RCGP data by summing the vaccine uptake within each month from September 2013 to August 2018 for all cohorts. 
To assess impact of the vaccine programme, we modelled the incidence of GP consultations as well as of hospital admissions according to age (in years), time period (2005 to 2018 for RCGP and 2008 to 2018 for HES) and vaccine eligibility. Vaccine eligibility is the factor that measures impact and we determined this for each incidence strata according to age and period and assigned this as not eligible, first eligible in that year (defined as $1^{\text {st }}$ October to $30^{\text {th }}$ September), and first eligible in 1, 2, 3 and 4 years previously. The reason for starting in October before measuring impact was to allow time for immunity to develop and to take into account low uptake in the September of each year. Individual vaccination status was therefore not used in this impact analysis, just eligibility by birth cohort. For the RCGP data we also assessed gender and region (London, Midlands, north England and south England) but did not include these in the final models as they did not change impact estimates.

We modelled the data using multivariable Poisson regression with an offset for person time. This model measures impact as the relative incidence in the vaccine eligible cohorts compared with unvaccinated cohorts. We investigated trends by age and period as linear, quadratic and cubic effects as well as an interaction effect between age and period, with the simplest model retained if the simplification did not result in more than a three percentage point change in impact estimates, although we retained a linear period effect in all models. To check robustness of impact estimates we fitted a random effects model with GP as the random effect as well as a model with age and period included as factors rather than polynomials.

To predict the expected incidence and number of events in the absence of vaccination we fitted the final model using data from the cohorts who were not eligible for vaccination and used this to extrapolate to the vaccine eligible cohorts. We also used this model to generate figures of observed compared with modelled incidence as well as a table of observed and expected numbers of events along with expected incidence and incidence reduction. We did sample size calculations prior to obtaining data to ensure reductions of $25 \%$ could be detected $(80 \%$ power and $5 \%$ significance). We estimated vaccine effectiveness (VE) consistent with impact and coverage by dividing the impact (percentage reduction) by the average cumulative coverage in the period/age cohort assessed. For example, a VE of $60 \%$ is consistent with a $30 \%$ reduction and $50 \%$ coverage. Precision of VE is based on the 95\% CIs for impact. We did all analyses in Stata 14.

\section{Patient and public involvement}

Patients or the public were not involved in the design or planning of the study.

\section{RESULTS}

\section{Vaccine uptake}

Uptake based on the 293 practices contributing to the RCGP RSC shows the routine cohorts in the first 4 years of the programme achieving about $60 \%$ to $65 \%$ uptake in the first year they are targeted and then having further gradual increases to over $75 \%$ (figure 1). The figure does show that more recent routine cohorts have achieved lower coverage, for example, by the August at the end of the first year targeted the first routine cohort (age 70 in September 2013 and vaccinated in 2013/2014) had $63 \%$ uptake compared with $46 \%$ for the fourth routine cohort (age 66 in September 2013 and vaccinated in $2017 / 2018$ ). The catch-up cohorts achieve $60 \%$ to $65 \%$ uptake which plateaus as they are no longer eligible once they reach age 80 (figure 2). Uptake in these practices was similar to that reported nationally which was $61.8 \%$,

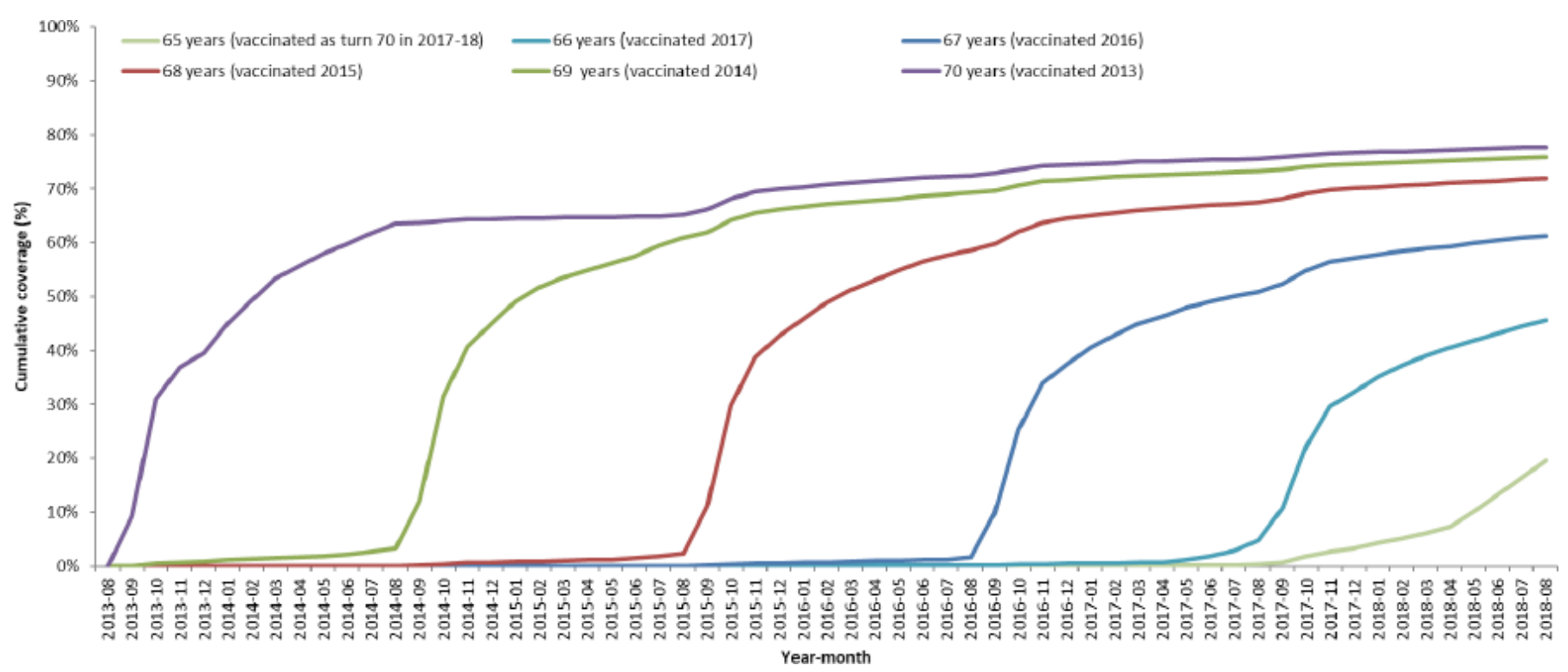

Figure 1 Cumulative coverage for each routine age cohort throughout 5-year vaccination programme. Cohorts are grouped by age on $1^{\text {st }}$ September 2013. 


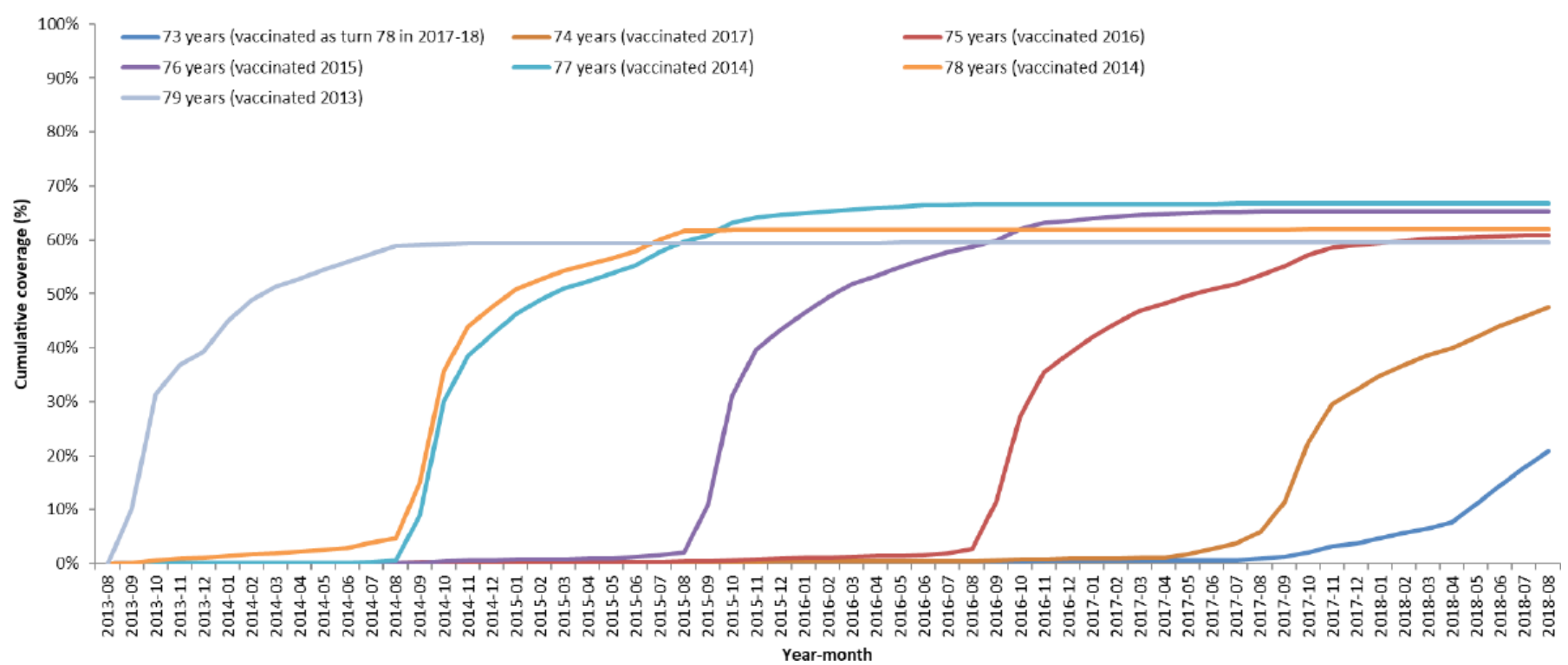

Figure 2 Cumulative coverage for each catch-up age cohort throughout 5-year vaccination programme. Cohorts are grouped by age on $1^{\text {st }}$ September 2013 .

$59.0 \%, 54.9 \%, 48.3 \%$ and $49 \cdot 1 \%$, respectively, for the first 5 years of the programme in the routine cohorts (aged 70, 69, 68, 67 and 66 years in September 2013) and $59 \cdot 6 \%, 57 \cdot 8 \%, 58 \cdot 5 \%, 55 \cdot 5 \%, 49 \cdot 4 \%$ and $50 \cdot 8 \%$, respectively, for the catch-up cohorts $(79,78,77,76,75$ and 74 years in September 2013). ${ }^{13-17}$

\section{Vaccine impact on GP consultations}

From the 293 RCGP practices the number of patients registered aged 60 to 89 years at October $1^{\text {st }}$ each year increased from 447567 in 2005 to 621993 in 2018 with an average of 542039 over the 14 years. These patients contributed a total 6.96 million person-years of data and are described in table 2 to show herpes zoster and PHN events and rates by vaccine eligibility, year and age. The incidence data were then modelled to estimate vaccine impact. Following the fitting process the final model included the variable to measure impact (vaccine eligibility), a log-linear time trend (a $0.2 \%$ increase per year, independent of age) and a quadratic age effect, with incidence increasing from 5.9 per 1000 person-years at 60 to a plateau of $10 \cdot 2$ by age 85 . No significant interactions were identified. The model with factors for age and period gave similar results, as did the random effects model.

Figures 3 and 4 show the observed and predicted incidence from the model in the absence of vaccination for herpes zoster and PHN by year (2005/2006 to $2017 / 2018$ ) for those cohorts aged between 66 years and 81 years as of $1^{\text {st }}$ September 2013. The figures clearly show the impact in the first year each cohort is targeted for vaccination and its persistence in the following years.

Cumulative uptake observed and predicted cases and relative incidence estimates from the fitted models are summarised for herpes zoster (table 3) and PHN (table 4). The tables also show the vaccine effectiveness required to generate the observed reductions, which is approximately $50 \%$ to $60 \%$ for herpes zoster. The incidence reduction, if applied to the England population translates to approximately 40500 fewer herpes zoster (including PHN) episodes over the study period. Reductions were greater for PHN (table 4 ) with a $47 \%$ reduction in PHN incidence in the routine cohorts across the first 5 years and a $38 \%$ reduction in the catch-up cohorts. This would be equivalent to a reduction in PHN episodes of 0.6 to 0.7 per 1000 person-years consistent with vaccine effectiveness of approximately $75 \%$ for routine and $66 \%$ for catch-up cohorts. The incidence reduction, if applied to the England population, translates to approximately 8700 fewer PHN episodes over the 5-year study period.

\section{Vaccine impact on hospitalisations}

A total of 117.5 million person-years of data for those diagnosed with herpes zoster and PHN aged 60 to 89 from October 2008 to September 2018 were included in the analysis of impact. Table 2 shows person-years and herpes zoster/PHN events contributed by cohorts eligible and not eligible for vaccination by year and age group. Modelling the hospitalisation incidence data indicated that the age followed a cubic trend and time-period a quadratic trend. The cubic age term allowed for a small decline in PHN incidence in the oldest ages $(>85)$ following the usual increase with age. The time trend showed increases over the period (table 2). As with GP consultations no significant interactions were identified and the models with factors for age and time effects and with GP random effects gave similar results.

Figures 5 and 6 show the observed and predicted incidence from the models in the absence of vaccination for herpes zoster and PHN by year (2008/2009 to 2017/2018) for those cohorts aged between 66 years and 81 years as of September 2013. The figures clearly show the impact in the first year each cohort is targeted for vaccination and in all the following years. Observed and predicted 


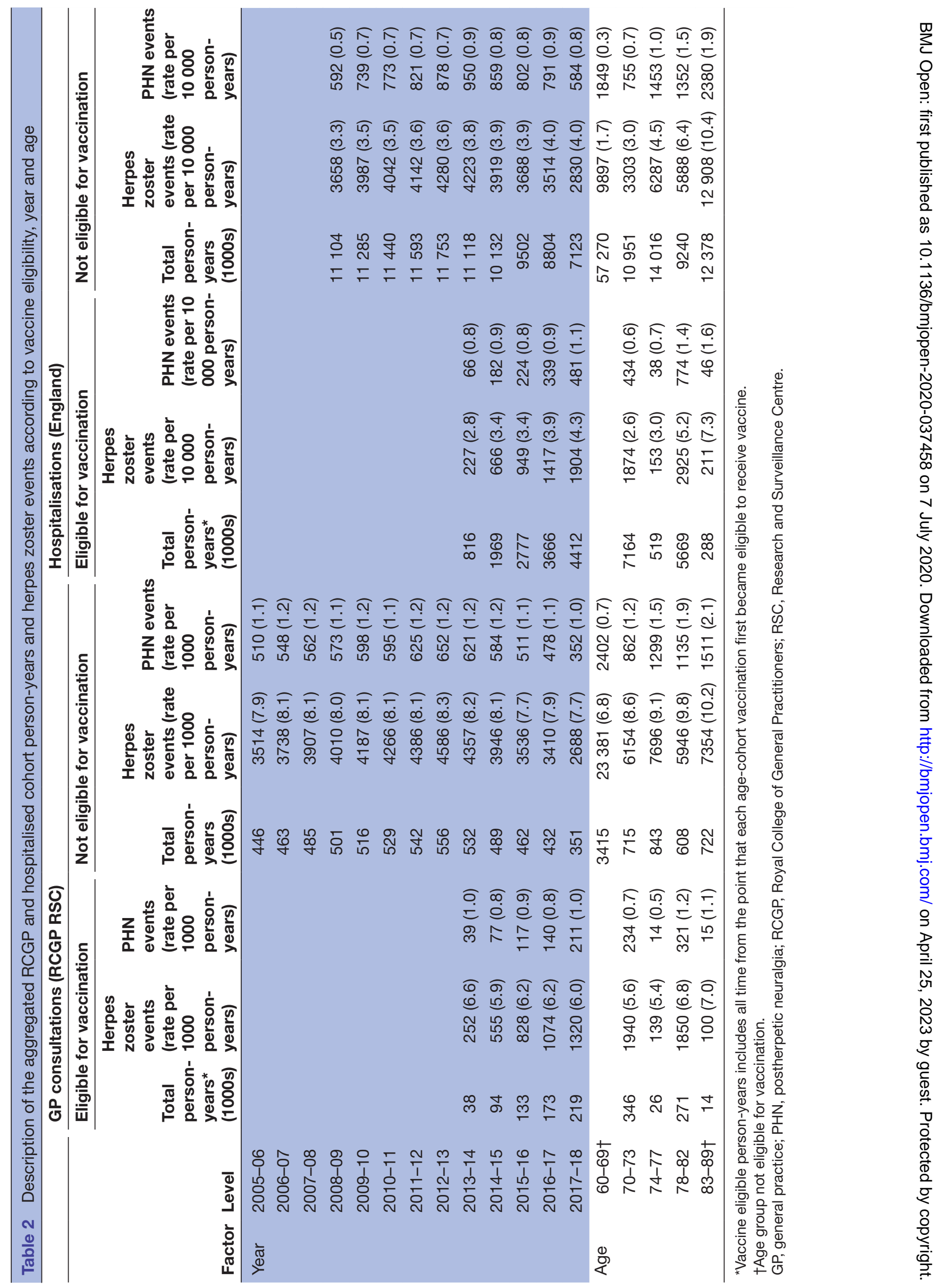




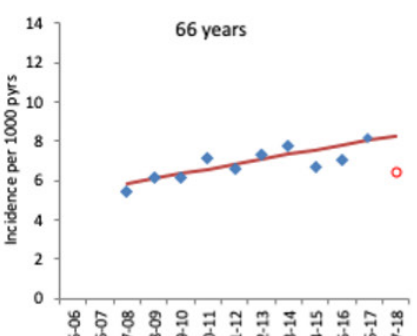

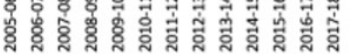
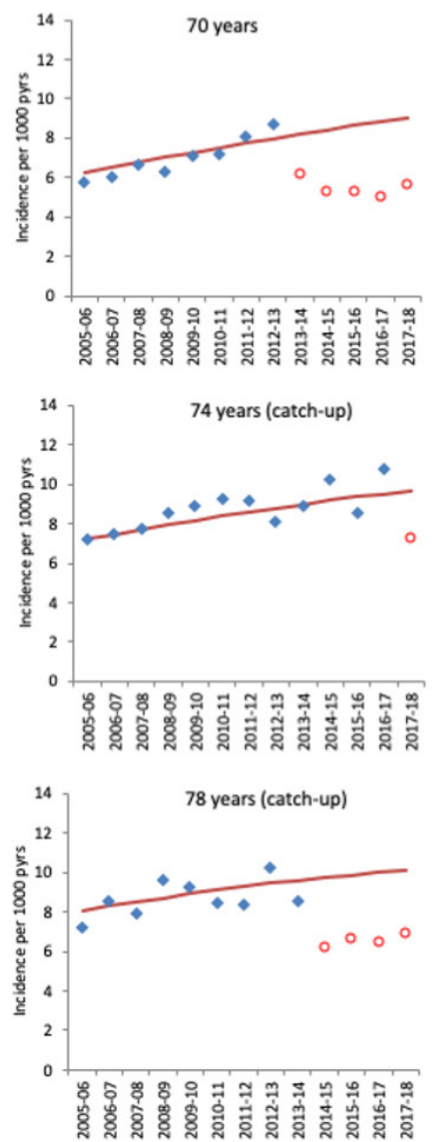

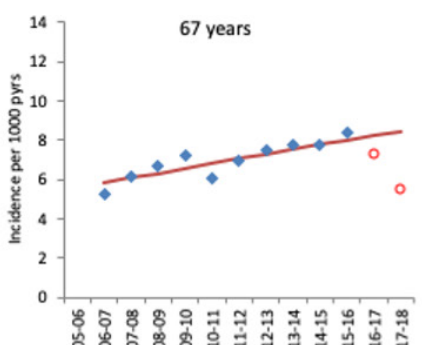

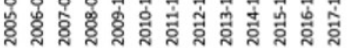
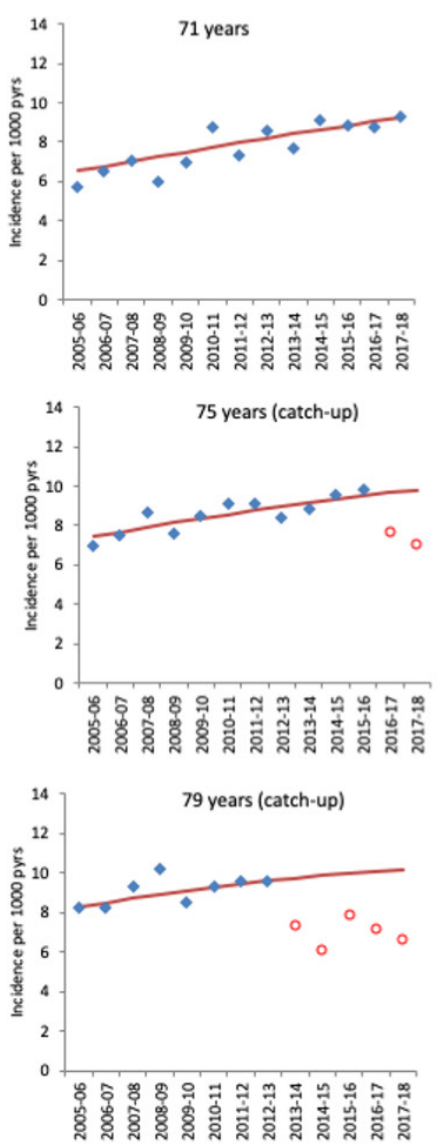
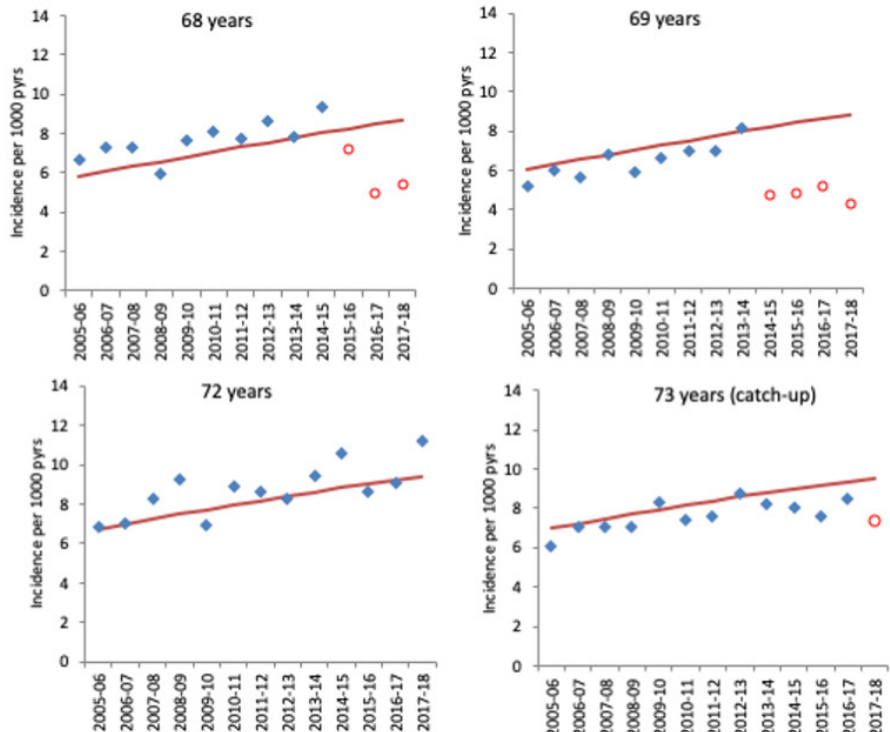

I11111111111
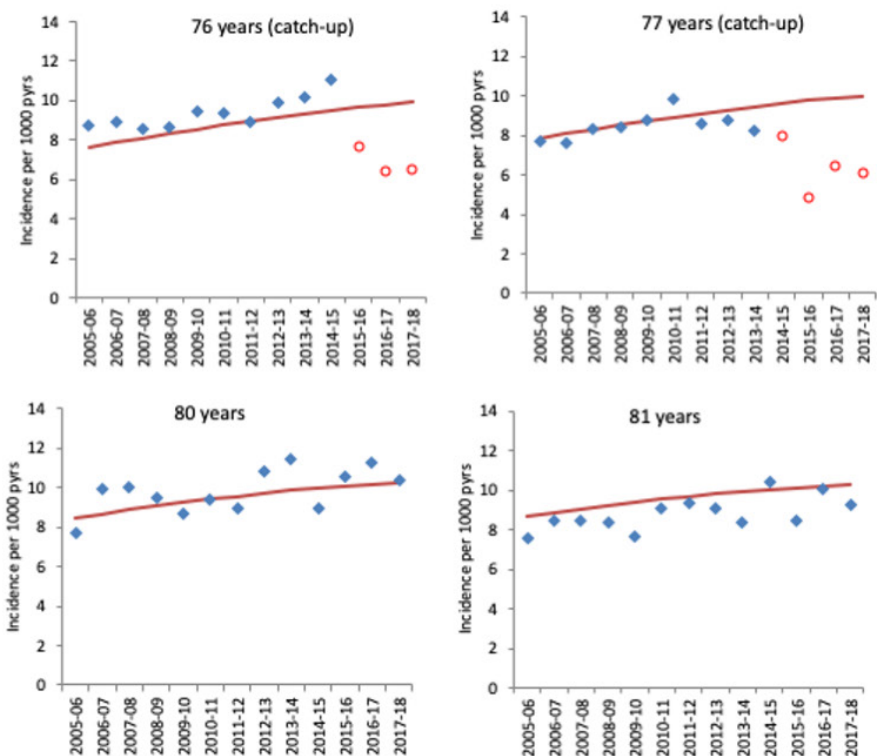

Figure 3 Observed GP-consulted herpes zoster incidence and model-predicted incidence in the absence of vaccination by year for each age cohort. Cohorts are grouped by age at 1 September 2013. Each year runs from October 1 of the first year to September 30 of the second. Blue points indicate observed zoster incidence and red points indicate observed incidence in age cohorts eligible for vaccination. Red lines show the model-predicted incidence in the absence of vaccination. Note that ages 71 , 72, 80 and 81 are cohorts not eligible in the period. GP,general practice.

cases and relative incidence estimates from the fitted models are summarised for herpes zoster (table 5) and PHN (table 6). Reduction for herpes zoster incidence were 23\% (range: 19 to 27 ) across the routine cohorts and 29\% (range: 26 to 32 ) across the catch-up cohorts in the 5 years of the programme. These relative reductions translated into incidence reductions of 0.78 per 10000 for routine and 2.1 per 10000 for catch-up cohorts and a total of 1840 prevented herpes zoster (including PHN) hospitalisations for the period 2013/2014 to 2017/2018.

Reductions were greater for PHN (table 6) with a $31 \%$ reduction in PHN incidence in the routine cohorts across the first 5 years and a $28 \%$ reduction in the catch-up cohorts. This would be equivalent to reduction in PHN episodes of 0.27 and 0.55 per 10000 person-years and gives an estimated number of PHN hospitalisations prevented of 540. Tables 5 and 6 also show the vaccine effectiveness of approximately $37 \%$ to $50 \%$ for herpes zoster and $50 \%$ for PHN, a little lower than that against GP consultations.

\section{DISCUSSION}

In this paper, we provide important evidence of the sustained population impact of the herpes zoster vaccination programme on GP consultations for herpes zoster and postherpetic neuralgia, 5 years following its implementation in England. Despite some challenges in programme implementation and accurately identifying eligible individuals for vaccination, our evaluation 

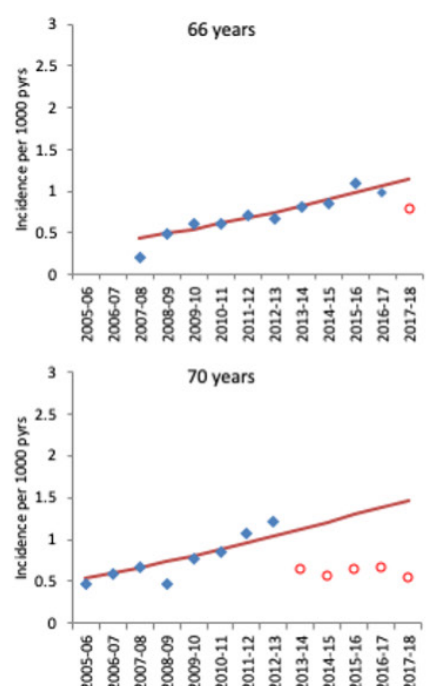

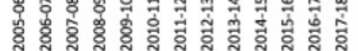
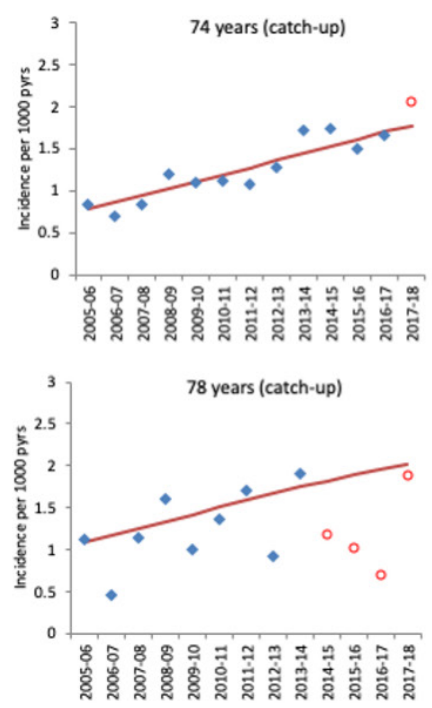
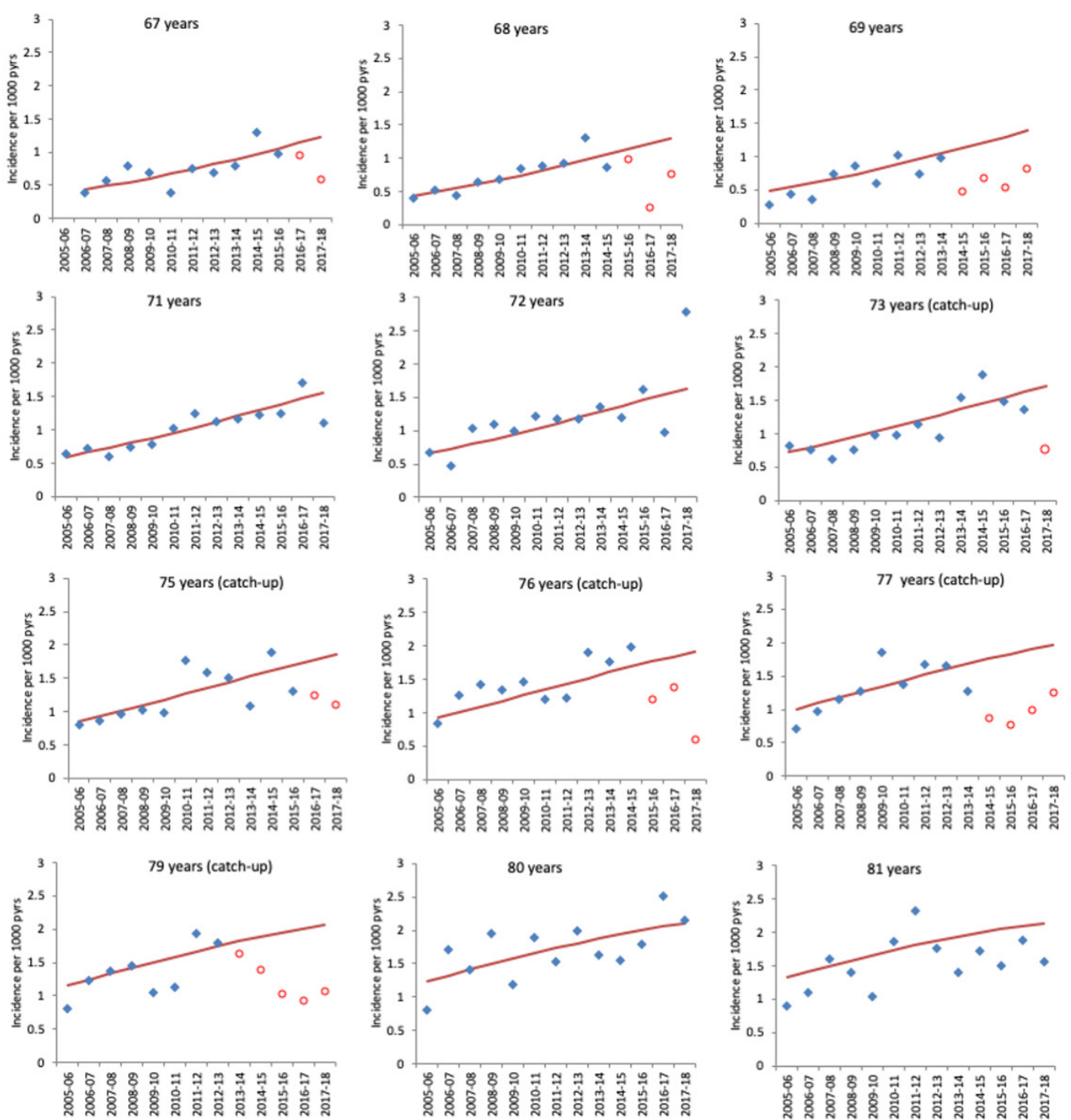

Figure 4 Observed GP-consulted postherpetic neuralgia incidence and model-predicted incidence in the absence of vaccination by year for each age cohort. Cohorts are grouped by age at 1 September 2013. Each year runs from October 1 of the first year to September 30 of the second. Blue points indicate observed zoster incidence and red points indicate observed incidence in age cohorts eligible for vaccination. Red lines show the model-predicted incidence in the absence of vaccination. Note that ages 71, 72, 80 and 81 are cohorts not eligible in the period. GP,general practice.

demonstrates the continued impact observed in the first cohorts targeted for vaccination in 2013/2014, indicating that the effectiveness of the vaccine programme has been maintained. This impact is equivalent to approximately 40 500 fewer GP consultations for herpes zoster and herpes zoster-related disease including 8700 fewer PHN consultations in the first 5 years of the national programme. These levels of disease prevention are particularly relevant in the context of a slowly increasing incidence of herpes zoster over time, reflecting changes in population demographics and is similar to trends observed in other countries. ${ }^{18}$

For the first time, we additionally demonstrate the impact of the vaccine programme on hospital admissions for herpes zoster and PHN with the impact of hospitalised herpes zoster at a rate similar to that observed for GP consultations for herpes zoster. In total, an estimated 1840 fewer herpes zoster hospitalisations including 540
PHN consultations were prevented in the first 5 years of the programme in England. The reduction in GP consultations and hospitalisations will have large cost savings. Using a cost of $£ 75 \cdot 60$ for a non-PHN GP case, £340.00 for a PHN GP case and £2816 for a hospitalised herpes zoster or PHN case gives a total cost saving of over 10.5 million pounds $(£ 75 \cdot 60 \times 31800+£ 340 \times 8700+£ 1840 \times 2816=£ 10$ 543520 ) over the first 5 years of the programme. These costs per case are derived from those used in recent costeffectiveness analysis (Alicia Rosello, personal communication) and the age distribution of the cases in our analysis. The average annual reduction in hospital costs $£ 1 \cdot 6$ million per year $((£ 340 \times 8700+£ 1840 \times 2816) \div 5)$ compares to an estimated cost prior to vaccination for herpes zoster hospitalisation of $£ 13$ million per year across all ages. ${ }^{19}$ These estimates of reduced burden and cost are likely to be conservative because they do not account for any lack of sensitivity in the coded episodes, 


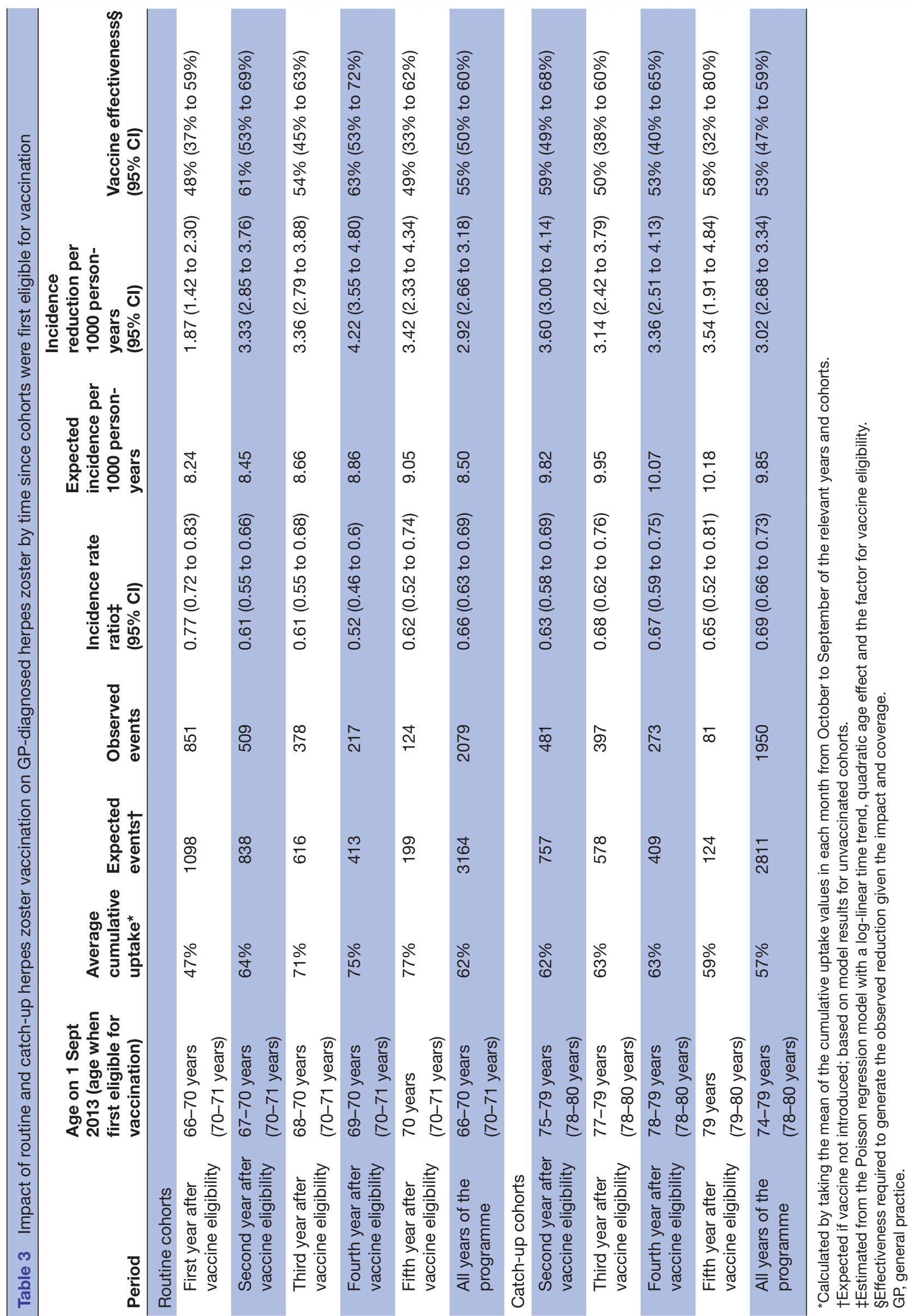




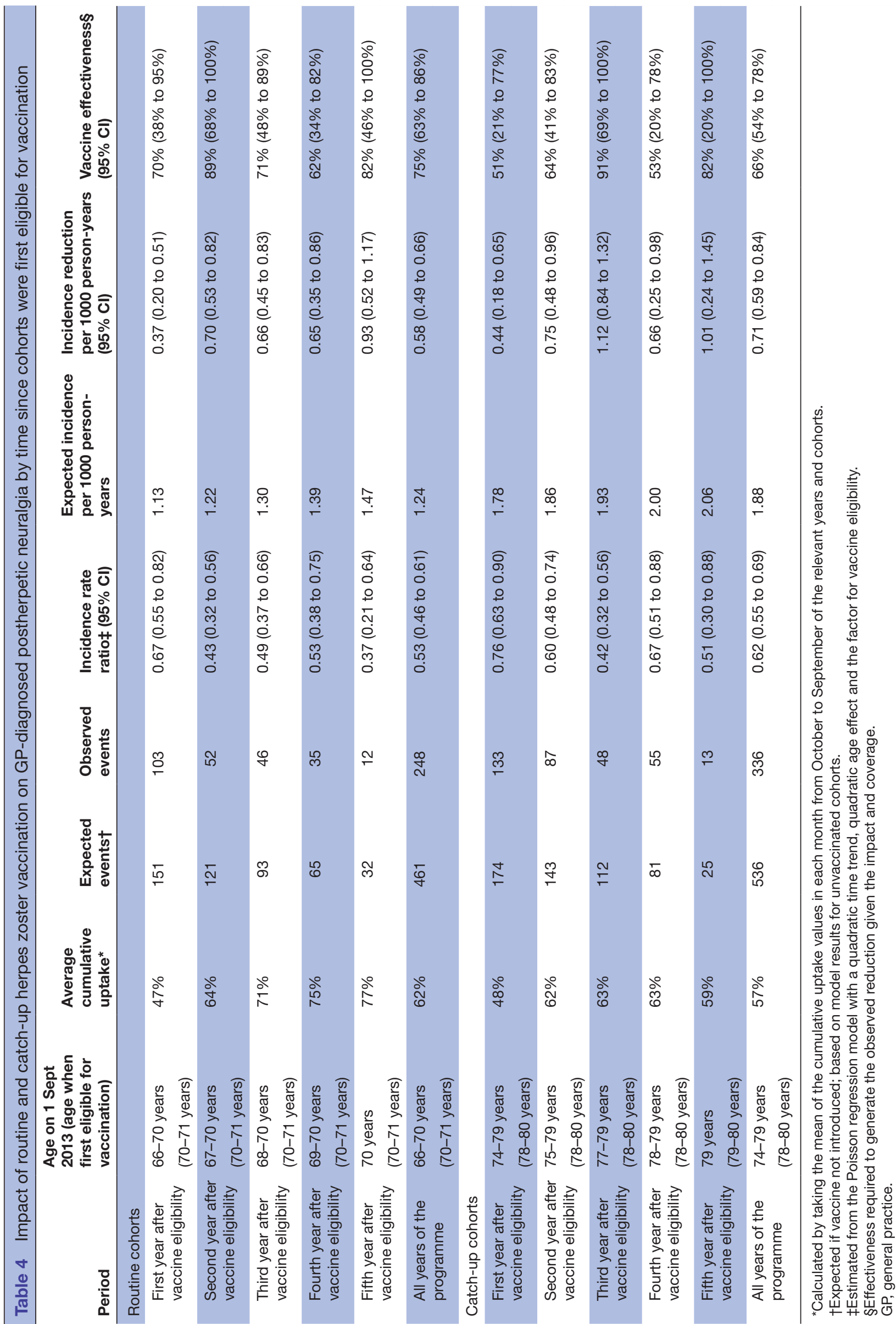



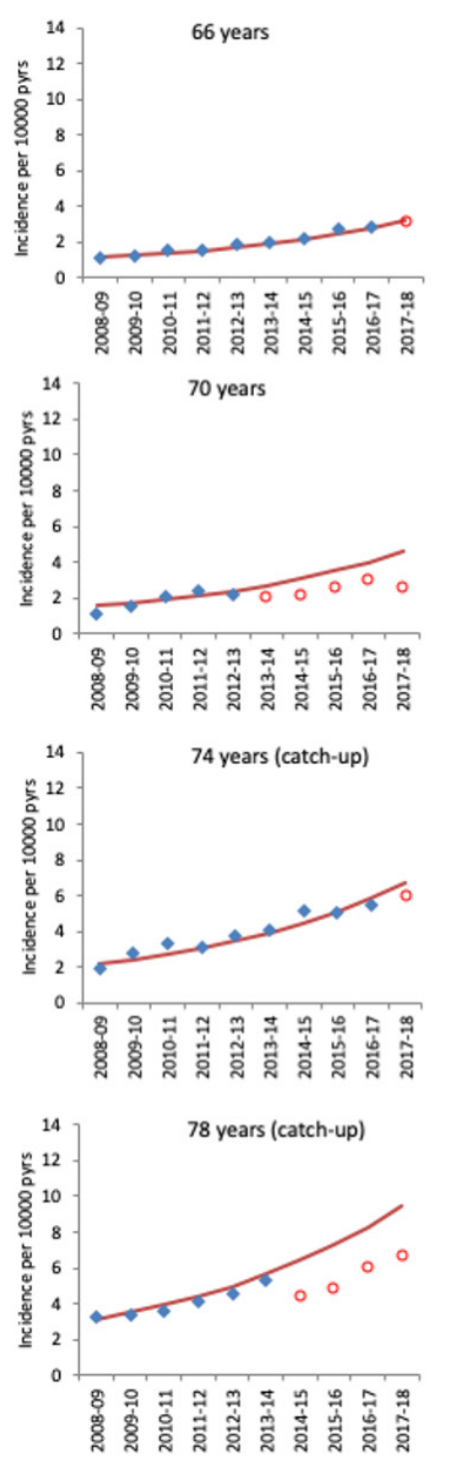
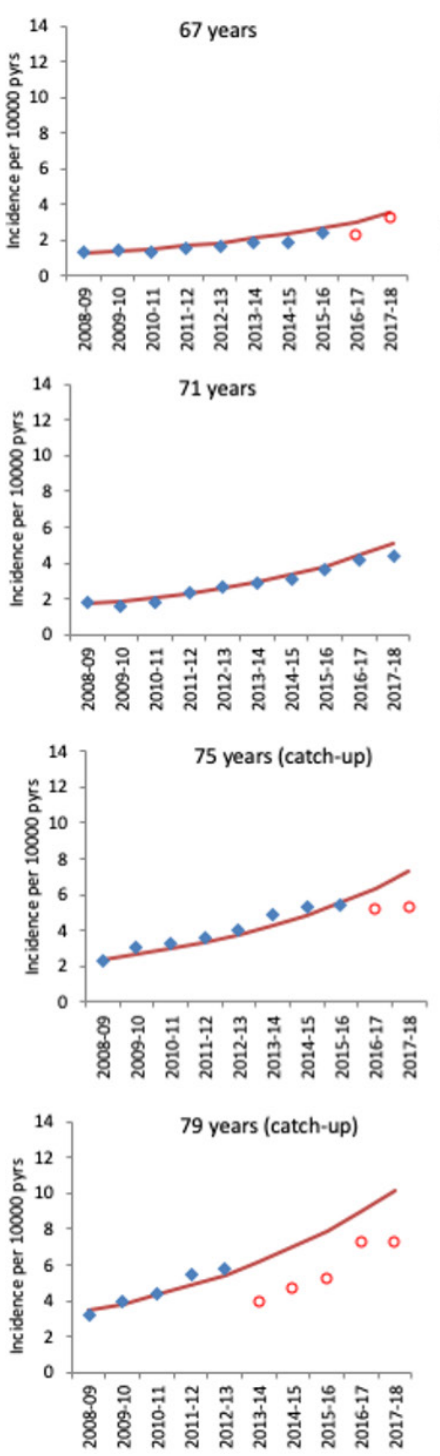
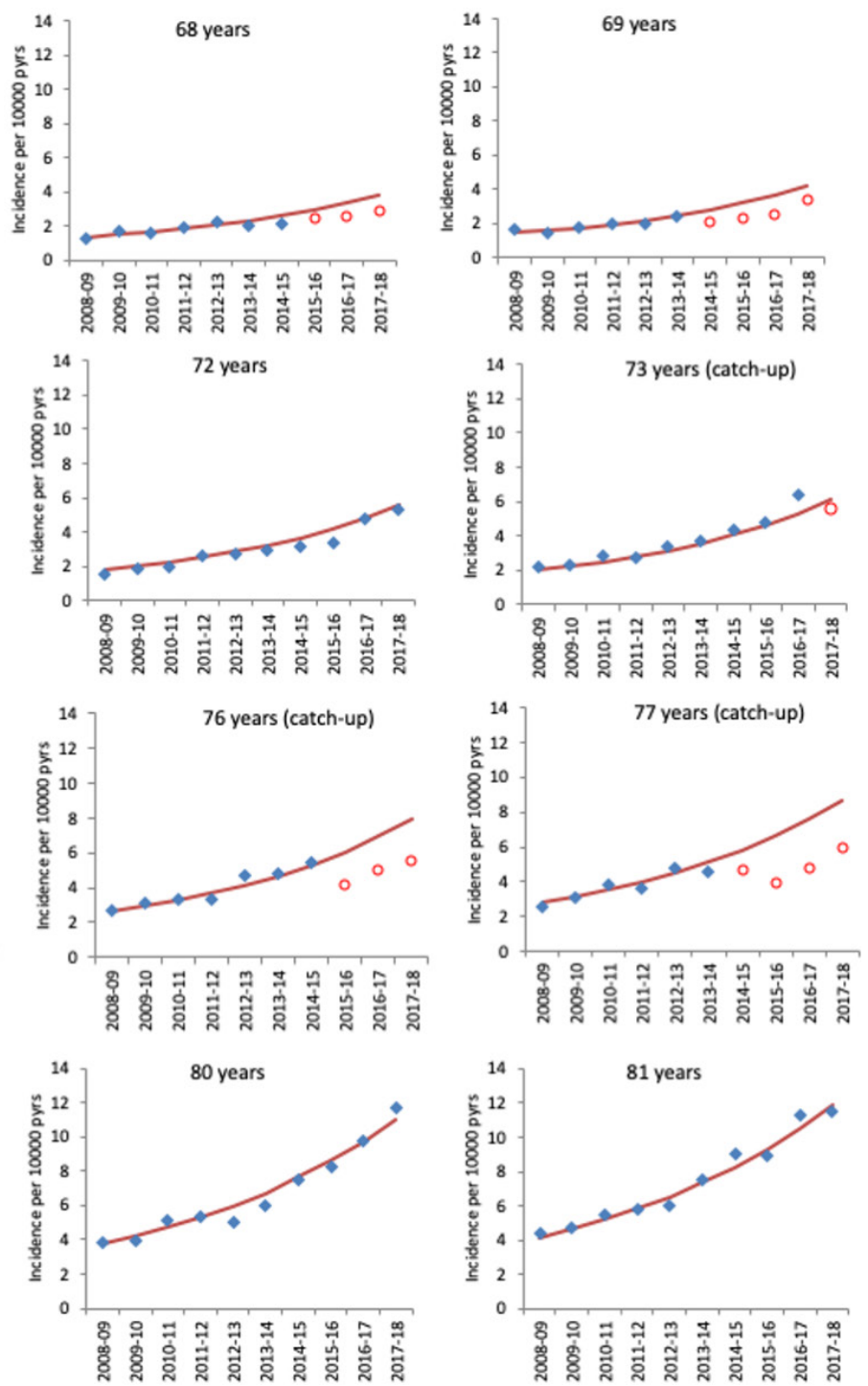

Figure 5 Observed hospitalised herpes zoster incidence and model-predicted incidence in the absence of vaccination by year for each age cohort. Cohorts are grouped by age at 1 September 2013. Each year runs from October 1 of the first year to September 30 of the second. Blue points indicate observed zoster incidence and red points indicate observed incidence in age cohorts eligible for vaccination. Red lines show the model-predicted incidence in the absence of vaccination. Note that ages 71 , 72,80 and 81 are cohorts not eligible in the period.

which is likely for PHN, and also do not allow for the fact that some individuals will have had repeat episodes with a year of one another as these were excluded to ensure episodes included were independent.

In our evaluation, the vaccine effectiveness against herpes zoster to generate the observed incidence reductions in GP consultations in the first 5 years following vaccination is approximately $50 \%$ to $60 \%$. This compares with long-term efficacy estimated from the long-term persistence study of approximately $38 \%$ and suggests that the protection from the vaccine does not wane as rapidly in clinical practice compared with the trial settings. ${ }^{45}$ In an 8-year follow-up cohort study in the US between 2007 and 2014, VE was $49.1 \%$ (95\% CI: 47.5 to $50 \cdot 6$ ) across all follow-up and VE waned from $67.5 \%$ during the first year after vaccination to $31 \cdot 8 \%$ (95\% CI: $15 \cdot 1$ to $45 \cdot 2$ ) by year $8 .{ }^{20}$ Our higher estimates may reflect differences in threshold for health seeking behaviour and the fact that milder cases may not present to general practice, although a US cohort study found lower effectiveness in outpatient data with a decline from $38 \%$ (95\% CI: 37 to 40) within a year of vaccination to $21 \%$ (95\% CI: 11 to 31) after seven or more years. ${ }^{21}$ That study found higher estimates and less waning for hospitalised zoster (VE 77\% (95\% CI: 39 to 67 ) within a year and 55\% (95\% CI: 39 to $67)$ at four or more years). Vaccine effectiveness against PHN was notably higher at $75 \%$ for routine cohorts and $66 \%$ for catch-up cohorts in the first 5 years of the programme in England. This is more closely aligned to the efficacy generated in the clinical trials with long-term efficacy of $67 \%$, as well as post licensure US studies of PHN with VE at about $50 \%$ between 4 and 7 years after vaccination. ${ }^{21} 22$ This effectiveness is consistent with evidence that the major benefits from this vaccine are through 

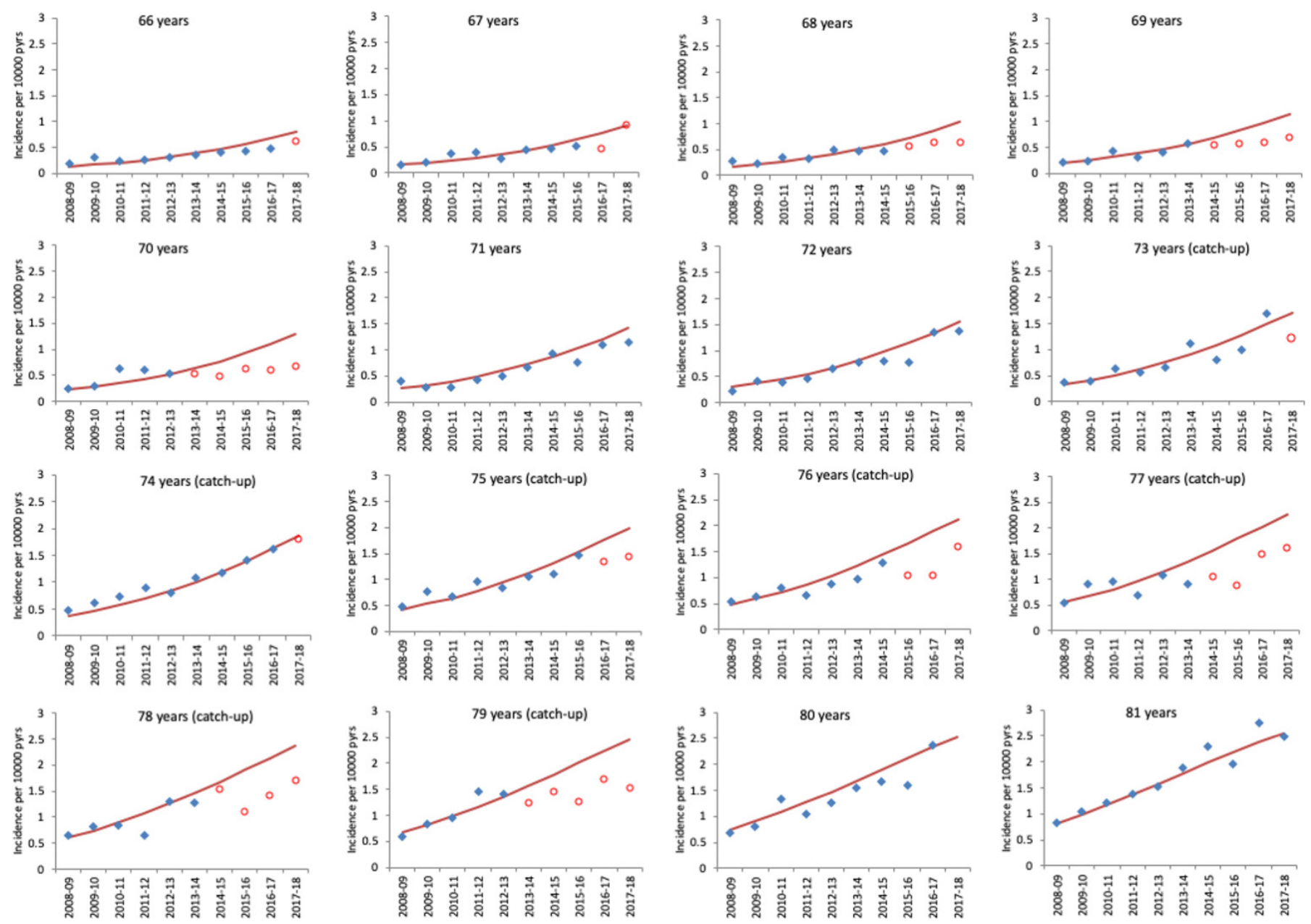

Figure 6 Observed hospitalised postherpetic neuralgia incidence and model-predicted incidence in the absence of vaccination by year for each age cohort. Cohorts are grouped by age at 1 September 2013. Each year runs from October 1 of the first year to September 30 of the second. Blue points indicate observed zoster incidence and red points indicate observed incidence in age cohorts eligible for vaccination. Red lines show the model-predicted incidence in the absence of vaccination. Note that ages $71,72,80$ and 81 are cohorts not eligible in the period.

preventing the complications from severe herpes zoster, rather than preventing herpes zoster itself. Our VE estimates are also similar to those estimated through a formal evaluation in the UK using a cohort design based on an alternative primary care data source. In that study VE was $64 \%$ (95\% CI: $60 \%$ to $68 \%$ ) against incident herpes zoster and $81 \%$ (95\% CI: $61 \%$ to $91 \%$ ) against PHN, with very similar VE estimates in the routine and catch-up cohorts and with some evidence of waning for the first 3 years of the programme. ${ }^{8}$ Similar results have also been reported in other primary care effectiveness studies in the UK with VE seen not to vary by age but being lower in those with type 2 diabetes or prior Zoster ${ }^{23}{ }^{24} \mathrm{~A}$ key strength of this study is the use of a large population-based sentinel primary care data source with robust historical data on consultations which are geographically representative of the country and provide consistent recording over time. In addition, the use of hospital admissions data across the whole of England add further weight to this evaluation. Despite this, it is important to note however, that in our study, time since first eligibility for vaccination is only an approximate measure of time since vaccination, particularly in the routine cohorts who continue to be eligible. Nevertheless, the continued low levels in the catch-up cohorts are particularly reassuring.

While, the findings from this 5-year evaluation are reassuring it is of concern that there has been a declining trend in vaccine uptake. Efforts to improve uptake have included simplifying the eligibility criteria for vaccination from April 2017 (ie, eligible on $70^{\text {th }}$ and $78^{\text {th }}$ birthday); although there are challenges in accurately monitoring uptake since this change, it is notable that as yet, this does not appear to have translated into a measurable improvement in uptake. To encourage improved uptake RCGP RSC has added feedback to member practices about their vaccine administration compared with the rest of the network as well as about rates of shingles and PHN; these data are also reported as a national observatory and show impact through the lower proportion of herpes zoster and PHN cases vaccinated than the whole eligible population. $^{25} 26$ 


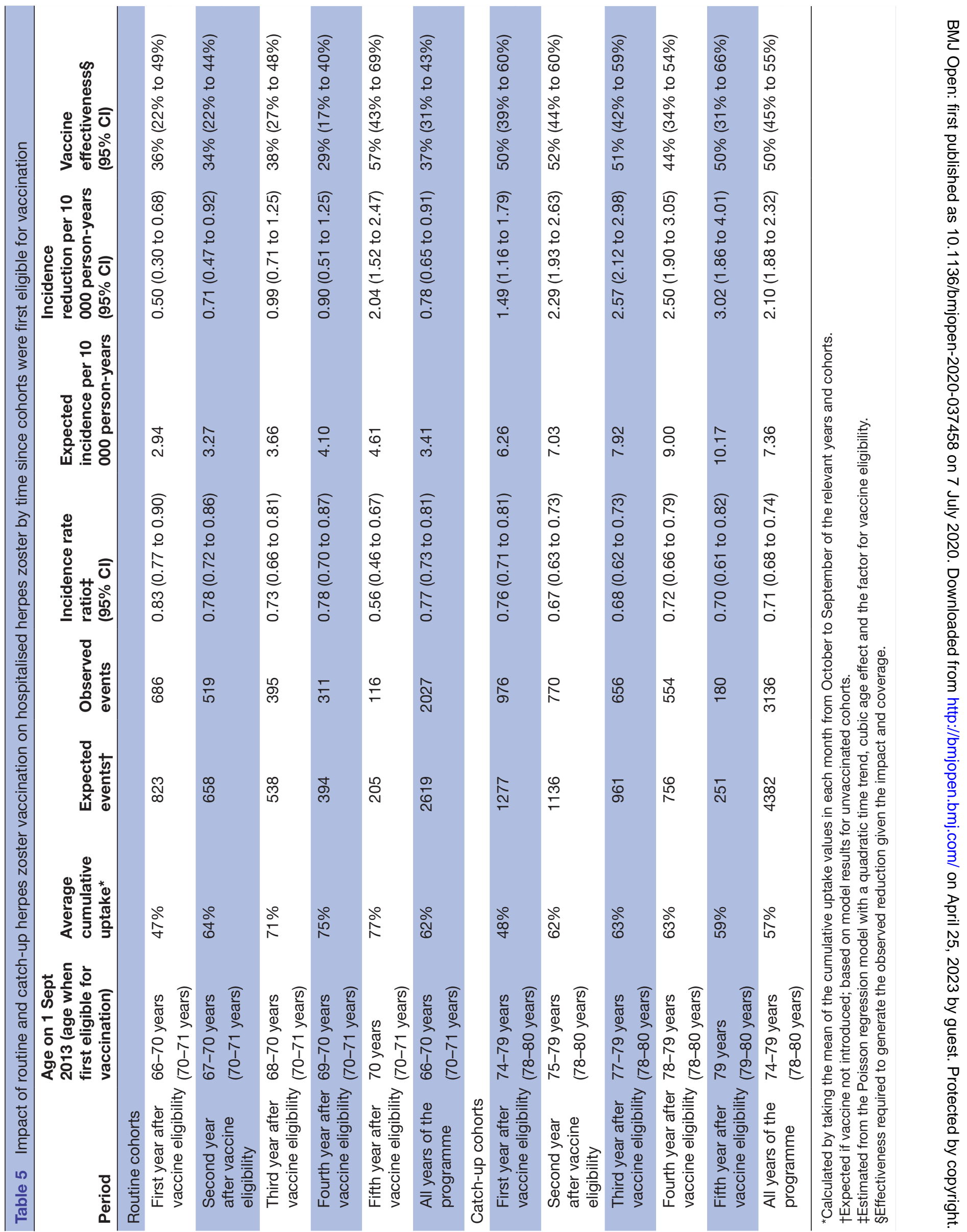




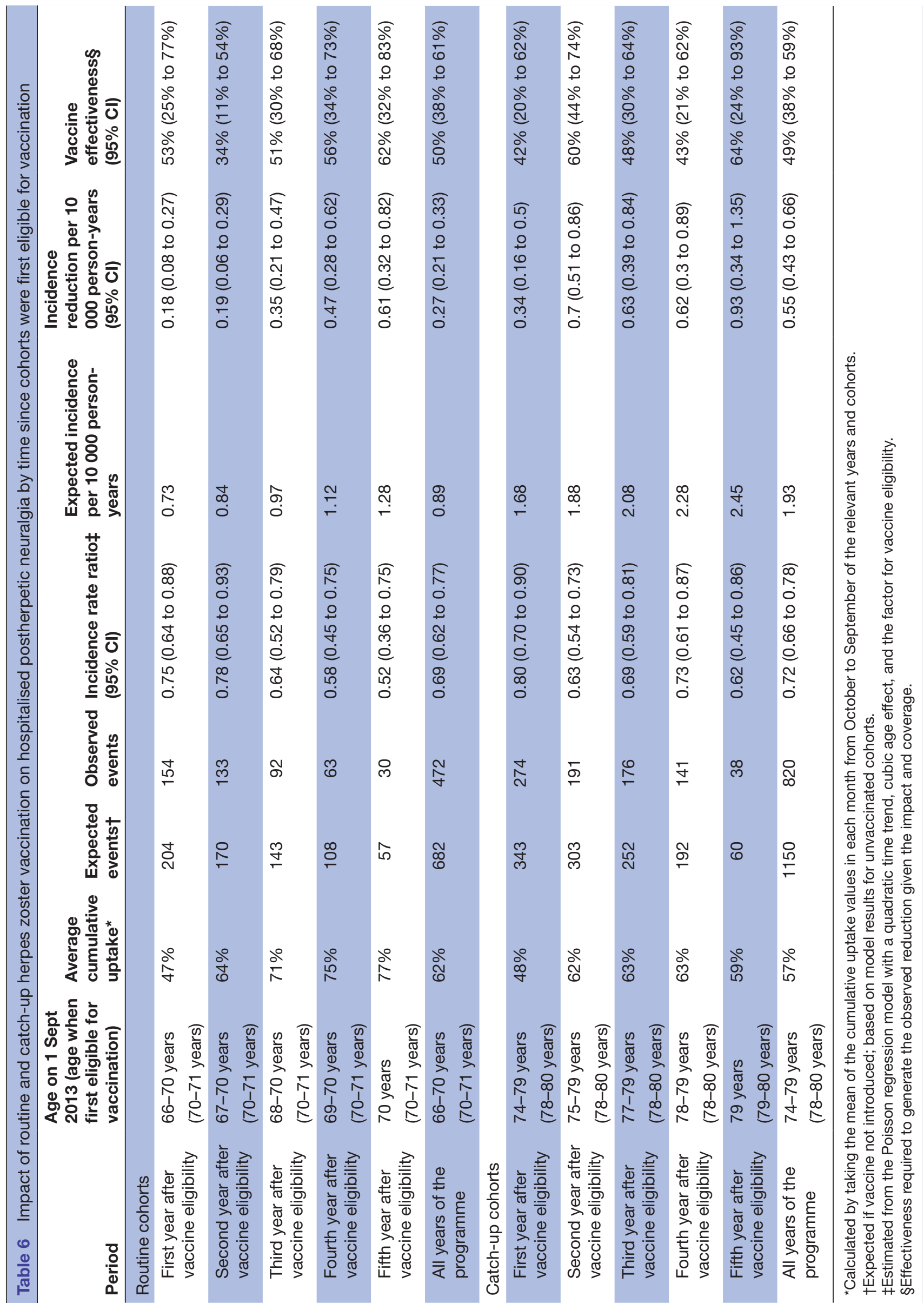

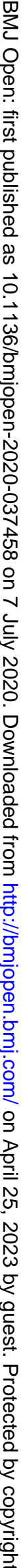


In 2019, the UK JCVI made specific recommendations for the use of a new recombinant subunit vaccine, Shingrix. ${ }^{27}$ This vaccine, licensed as a two-dose schedule, administered at 2- to 6-month intervals, has been shown to have efficacy of $>90 \%$ in older adults with limited waning to 4 years and has been introduced into the US programme in $2018 .^{28}$ As a recombinant vaccine, this vaccine is being recommended in the UK, for use in immunocompromised individuals known to be at high risk of herpes zoster and currently unable to benefit from the existing herpes zoster vaccination programme. In addition, Shingrix has been recommended for use in the routine programme for adults aged 60 to 70 years based on a recent cost-effectiveness analysis. However due to the limited availability to meet high global demand, it is currently not known when Shingrix will be available for use in the UK programme.

The findings from this evaluation of the current herpes zoster vaccination programme in England however should provide considerable reassurance to health professionals and patients and serves as a reminder of the significant health benefits conferred to a target population that is both increasing in size and that is particularly affected from the severe consequences of herpes zoster and herpes zoster-related complications.

\section{Twitter Simon de Lusignan @Lusignan_S}

Acknowledgements This study was supported by Public Health England. The patients and practices of the RCGP RSC who allow their pseudonymised clinical medical records data to be used for this study. The authors also wish to thank colleagues at the RCGP RSC secure data and analytics hub at University of Surrey. We thank Alicia Rosello for assistance with the costs calculation of hospitalised and GP consulted herpes zoster.

Contributors NA, GA, IY, SdL and MR were all involved in the concept and design of the evaluation of the herpes zoster vaccination programme. IY and SdL were responsible for providing the RCGP data. JS, BS and GK were responsible for extracting the HES data. NA, JS, IY and BS analysed the data. NA drafted the paper and all authors were involved in the revision. All authors approved the final version and agree to be accountable for all aspects of the work. The corresponding author attests that all listed meet authorship criteria and that no others meeting the criteria have been omitted.

Funding This work was supported by Public Health England.

Competing interests The authors declare the following financial interests/ personal relationships which may be considered as potential competing interests: SdeL has received University funding for studies of post vaccination adverse events of interest from GSK, and for attitudes to vaccination from Seqirus; and has been a member of Seqirus and Sanofi advisory boards. Public Health England, National Infection Service, Immunisation and Countermeasures Division has provided vaccine manufacturers with post-marketing surveillance reports, which the Marketing Authorisation Holders are required to submit to the UK licensing authority in compliance with their Risk Management Strategy. A cost recovery charge is made for these reports.

Patient consent for publication Not required.

Provenance and peer review Not commissioned; externally peer reviewed.

Data availability statement Data may be obtained from a third party and are not publicly available. No data are available. The general practice data were obtained from the Royal College of General Practitioners Research and Surveillance. For the hospital (HES) data this work was carried out under Regulation 3 of The Health Service (Control of Patient Information) (Secretary of State for Health, 2002). Data cannot be made publicly available for ethical and legal reasons, that is, public availability would compromise patient confidentiality as data tables would include aggregated counts with very small numbers.
Open access This is an open access article distributed in accordance with the Creative Commons Attribution Non Commercial (CC BY-NC 4.0) license, which permits others to distribute, remix, adapt, build upon this work non-commercially, and license their derivative works on different terms, provided the original work is properly cited, appropriate credit is given, any changes made indicated, and the use is non-commercial. See: http://creativecommons.org/licenses/by-nc/4.0/.

\section{ORCID iDs}

Nick Andrews http://orcid.org/0000-0003-2069-2684

Simon de Lusignan http://orcid.org/0000-0001-5613-6810

\section{REFERENCES}

1 van Hoek AJ, Gay N, Melegaro A, et al. Estimating the costeffectiveness of vaccination against herpes zoster in England and Wales. Vaccine 2009;27:1454-67.

2 Joint Committee on Vaccination and Immunisation. Statement on varicella and herpes zoster vaccines. Available: http://webarchive. nationalarchives.gov.uk/20120907090205/http://www.dh.gov.uk/ prod_consum_dh/groups/dh_digitalassets/@dh/@ab/documents/ digitalasset/dh_133599.pdf

3 Public Health England. Immunisation against infectious disease, the greenbook; chapter 28a shingles (herpes zoster). Available: https:// www.gov.uk/government/uploads/system/uploads/attachment_data/ file/503773/2905109_Green_book_Chapter_28a_v3_OW.PDF

4 Oxman MN, Levin MJ, Johnson GR, et al. A vaccine to prevent herpes zoster and postherpetic neuralgia in older adults. $N$ Engl $J$ Med 2005;352:2271-84.

5 Morrison VA, Johnson GR, Schmader KE, et al. Long-term persistence of zoster vaccine efficacy. Clin Infect Dis 2015;60:900-9.

6 de Lusignan S, Correa A, Pathirannehelage S, et al. RCGP research and surveillance centre annual report 2014-2015: disparities in presentations to primary care. Br J Gen Pract 2017;67:e29-40.

7 Amirthalingam G, Andrews N, Keel P, et al. Evaluation of the effect of the herpes zoster vaccination programme 3 years after its introduction in England: a population-based study. Lancet Public Health 2018;3:e82-90.

8 Walker JL, Andrews NJ, Amirthalingam G, et al. Effectiveness of herpes zoster vaccination in an older United Kingdom population. Vaccine 2018;36:2371-7.

9 Correa A, Hinton W, McGovern A, et al. Royal College of general practitioners research and surveillance centre (RCGP RSC) sentinel network: a cohort profile. BMJ Open 2016;6:e011092.

10 de Lusignan S, Codes deLS. Codes, classifications, terminologies and nomenclatures: definition, development and application in practice. Inform Prim Care 2005;13:65-9.

11 Hospital Episode Statistics (HES), Health and Social Care Information Centre. Re-used with the permission of the health and social care information centre. Available: http://www.hscic.gov.uk/hesdata

12 Office for National Statistics. Population estimates unit. estimated resident population mid year. Available: https://www.ons.gov. $\mathrm{uk} /$ peoplepopulationandcommunity/populationandmigration/ populationestimates

13 Public Health England. Herpes zoster (shingles) immunisation programme 2013 to 2014: evaluation report. Available: https:// www.gov.uk/government/publications/herpes-zoster-shinglesimmunisation-programme-2013-to-2014-evaluation-report

14 Public Health England. Herpes zoster (shingles) immunisation programme 2014 to 2015: evaluation report. Available: https:// www.gov.uk/government/publications/herpes-zoster-shinglesimmunisation-programme-2014-to-2015-evaluation-report

15 Public Health England. Herpes zoster (shingles) immunisation programme 2015 to 2016: evaluation report.. Available: https://www. gov.uk/government/uploads/system/uploads/attachment_data/file/ 572391/Shingles_annual_2015_to_2016.pdf

16 Public Health England. Herpes zoster (shingles) immunisation programme: September 2016 to August 2017: report for England. Available: https://assets.publishing.service.gov.uk/government/ uploads/system/uploads/attachment data/file/667636/Annual shingles_report_2016-2017_.pdf

17 Public Health England. Cumulative shingles vaccine coverage report to end of June 2019 (quarter 4) and annual 2018 to 2019 coverage: England. Available: https://assets.publishing.service.gov.uk/ government/uploads/system/uploads/attachment_data/file/827016/ hpr3019_shnglsVC.pdf

18 Kawai K, Gebremeskel BG, Acosta CJ. Systematic review of incidence and complications of herpes zoster: towards a global perspective. BMJ Open 2014;4:e004833. 
19 Hobbelen PHF, Stowe J, Amirthalingam G, et al. The burden of hospitalisation for varicella and herpes zoster in England from 2004 to 2013. J Infect 2016;73:241-53.

20 Baxter R, Bartlett J, Fireman B, et al. Long-term effectiveness of the live zoster vaccine in preventing shingles: a cohort study. Am J Epidemiol 2018;187:161-9.

21 Bollaerts K, Alexandridou M, Verstraeten T. Risk factors for modified vaccine effectiveness of the live attenuated zoster vaccine among the elderly in England. Vaccine X 2019;1:100007.

22 Matthews I, Lu X, Dawson H, et al. Assessing the effectiveness of zoster vaccine live: a retrospective cohort study using primary care data in the United Kingdom. Vaccine 2018;36:7105-11.

23 Izurieta HS, Wernecke M, Kelman J, et al. Effectiveness and duration of protection provided by the live-attenuated herpes zoster vaccine in the medicare population ages 65 years and older. Clin Infect Dis 2017;64:785-93.
24 Klein NP, Bartlett J, Fireman B, et al. Long-term effectiveness of zoster vaccine live for postherpetic neuralgia prevention. Vaccine 2019;37:5422-7.

25 Pathirannehelage S, Kumarapeli P, Byford R, et al. Uptake of a dashboard designed to give RealTime feedback to a sentinel network about key data required for influenza vaccine effectiveness studies. Stud Health Technol Inform 2018;247:161-5.

26 RCGP RSC. Workload observatory. Available: https://clininf.eu/index. php/rcgprscworkloadobservatory/

27 Joint Committee on Vaccination and Immunisation. Minute of the meeting held on 06 February 2019. Available: https://app.box.com/s/ iddfb4ppwkmtjusir2tc/file/424913874479

28 Cunningham AL, Lal H, Kovac M, et al. Efficacy of the herpes zoster subunit vaccine in adults 70 years of age or older. $N$ Engl $J$ Med 2016;375:1019-32. 